\title{
Volcanic spherules indicative of carbonate silicate liquid immiscibility in the Payenia volcanic province, Argentina
}

\author{
LINDA A. KIRSTEIN ${ }^{1}$; SILVESTAR KANEV ${ }^{1}$; J. GODFREY \\ FITTON $^{1}$; STEPHEN J. TURNER ${ }^{2}$ \\ ${ }^{1}$ School of GeoSciences, University of Edinburgh, \\ Edinburgh, EH9 3FE, UK \\ ${ }^{2}$ Washington University in St. Louis, One Brookings Drive, \\ St. Louis, MO 63130, USA
}

Spherules can be formed by high temperature processes during volcanic eruptions, lightning strikes, meteorite impacts and nuclear explosions. Here we report on different types of spherules associated with tephra deposits from two separate volcanic fields in the southern Payenia region of Argentina. These silicate and carbonate spherules represent $<1 \%$ of the sampled material with individual spherules $<200 \mu \mathrm{m}$ in size. There are four distinct types of spherules identified. Only the transparent spherules are smooth, perfect spheres. Other morphologies include ellipsoids and aggregated dumbbells and all spherules are either hollow or solid. The majorelement components of the spherules have been analysed and include silica-rich, iron-rich, calcitic and basaltic compositions. All spherules are considered volcanic in origin, with excess carbonate from basement lithologies.

The four different types of spherule found in tephra from the Payenia volcanic province of the Andes are all volcanic in origin and form as a result of initial degassing and segregation followed by post-eruptive condensation processes. Their compositions are distinctly different from spherules formed by extra-terrestrial impact processes. The spherule compositions are diverse ranging from high $\mathrm{Si}$ glasses to silicate melts similar in composition to the host tephra, and from carbonate to Fe-Ti rich globules. Magmatic $\mathrm{CO} 2$, and carbonate-enriched magmas formed through interaction with carbonate in the basement are key to the formation of the carbonate and Si-rich spherules. We conclude that mechanisms including rapid condensation on eruption led to the formation of the spherules from supercritical and immiscible carbonate-silicate liquids. 